\title{
Critical care by emergency physicians in American and English hospitals
}

\author{
L. G. GRAFF*t, S. CLARK $\ddagger$ \& M. J. RADFORD*
}

${ }^{*}$ University of Connecticut Medical School, Farmington, Connecticut, ${ }^{+}$New Britain General Hospital, New Britain, Connecticut and ${ }^{\ddagger}$ Queens Medical Centre, Nottingham.

\section{SUMMARY}

The object of this study was to compare emergency physician critical care services in an American (A) and an English (E) Emergency Department (ED). A prospective case comparison trial was used. The study was carried out at two university affiliated community hospitals, one in the U.S.A and one in England. Subjects were consecutive patients triaged as requiring critical care services and subsequently admitted to the hospital ward (A, $n=17 ; \mathrm{E}, n=18)$ or the intensive/ critical care unit ([ICU] A, $n=14 ; \mathrm{E}, n=24$ ). The study time period was randomly selected 8-h shifts occurring over a 4-week period. All patients were treated by standard guidelines for critical care services at the study hospital emergency department. For all study patients mean length of stay was significantly longer for the American (233 min, 95\% CI 201, 264) than the English ED (24 min, $95 \%$ CI 23, 25). American emergency physicians spent less total time providing physician services $(19.2 \mathrm{~min}, 95 \%$ CI 16.8, 21.6) vs. (23 min, 95\% CI 21.6, 24.4) than English emergency physicians. American emergency physicians spent less time with the patient than English emergency physicians: $12.4 \mathrm{~min}(95 \%$ CI 10.3, 14.5) vs. $17 \mathrm{~min}$ $(95 \%$ CI 15.8, 18.2). American emergency physicians spent more time on the telephone $1.8 \mathrm{~min}(95 \% \mathrm{CI} 1.4,2.2)$ vs. $1.2 \mathrm{~min}(95 \% \mathrm{CI} 1.1,1.3)$, and in patient care discussions/order giving $1.8 \mathrm{~min}(95 \% \mathrm{CI} 1.4,2.2)$ vs. $1.1 \mathrm{~min}(95 \% \mathrm{CI} .8,1.4)$. There was no significant difference in time charting $(3.2 \mathrm{~min}, 95 \% \mathrm{CI} 2.8,3.6$ vs. $3.5 \mathrm{~min}, 95 \%$ CI $3.2,3.8$ ). Results did not vary significantly whether analysed by subgroups or the whole study group. American emergency physicians provided $81 \%$ of their service during the first hour. There were delays at the American hospital until the physician saw the patient: $4.9 \mathrm{~min}(95 \% \mathrm{CI} 2.5,7.3)$ for patients admitted to the ICU/CVU (Cardiovascular Unit), and $9.2 \mathrm{~min}(95 \% \mathrm{CI} 4.6,13.8)$ for patients admitted to the ward. At the American hospital, ICU/CVU physicians provided additional physician services in the emergency department whether the patient was admitted to the ward $(6.7 \mathrm{~min}, 95 \%$ CI $5.5,7.9)$ or the ICU/CVU 
(12.1 min, 95\% CI 8.8, 15.9). For patients admitted to the ICU/CVU $47 \%$ of the length of stay was spent waiting for a bed to become available after the decision to admit had been made. Emergency physicians at E provided critical care services almost continuously during a short stay in the ED. Emergency physicians at A provided services intermittently with most services during an initial period of stabilization. Further study is necessary to identify what factors contribute to these different approaches to critical care in the ED.

\section{INTRODUCTION}

Critically ill patients have a major impact upon EDs. They are given priority so they quickly receive the intensive level of services they need (Saunders, 1987). They are initially identified by nurse triage which has been the standard for EDs since the early 1970's (Weinerman et al., 1966; Baldridge, 1966; Graves, 1972; Rosen et al., 1974; Vickery, 1975). While this type of patient makes up only a small portion of ED visits (1-12.6\%) (Kluge et al., 1965; Gibson, 1970; Jacobs et al., 1971; Walker, 1975; Engstrom, 1977; Parker, 1978; Mendenhall, 1979; Gifford et al., 1980; LeTourneall et al., 1980; Saunders, 1987), they require a large portion of departmental resources due to their high intensity of service needs. Once they have had a period of evaluation and stabilization, these patients are admitted to the hospitaf for continuation of their care.

Emergency departments in America and England both manage critically id patients. Yet, there are many differences between the health care systems of the two countries (Rutherford, 1983; Navarro, 1985; Reinhardt, 1985; Lister, 1986). The objective of this study was to examine for differences in the delivery of emergency physician critical care services in an A and an E ED.

\section{METHODS}

This was a prospective study of consecutive patients requiring critical care services in the ED and subsequently admitted to the hospital. Each hospital had nurse triage systems with patients identified on arrival in the ED as critical, emergent, urgent or non-urgent. Patients triaged as emergent and subsequently admitted to the critical care unit (CCU) or hospital ward were included in the study. The patients were collected from randomly selected ED shifts over a 4-week period at each hospital.

At A 31 study patients were entered with 17 admitted to the hospital ward and 14 to the CCU. Thirty-seven other patients were excluded at A. Nineteen of these patients were excluded because they were initially triaged as emergent but subsequently were not admitted to the hospital. Seventeen of these patients were excluded because they were transferred to an ED observation bed for a mean of $12 \mathrm{~h}$ of observation before the decision on disposition. The observation services are ED services in addition to the initial evaluation and stabilization of the 
patient. Only one-third of American hospitals have ED observation beds such as in the study hospital with the other hospitals admitting or discharging patients after the initial evaluation (Yealy et al., 1989). Three of the 17 observation patients were admitted after observation and 14 of the 17 were discharged home without hospital admission after observation. The diagnoses of those patients discharged were: ten with chest pain; two with hematemesis; one with seizure; and one with palpitations. One patient was excluded who presented to the ED as a cardiopulmonary arrest. This type of patient service was also considered different to the study population. Cardiopulmonary arrest patients are triaged as critical, and not as emergent, on their presentation. Also only $20-30 \%$ are successfully resuscitated to be admitted to the hospital in contrast to the critical care patients who are, by definition, patients admitted to the hospital.

At E, 42 study patients were entered into the study with 18 admitted to the hospital ward and 24 to the CCU. Three other patients, who presented to the hospital with cardiopulmonary arrest, were excluded.

The study hospitals were university affiliated community hospitals in the United States and in England. Staffing at A was by two or three full-time emergency physicians with one or two medical house officers (1-3 years after medical school). The staffing at $\mathrm{E}$ was by five or six senior house officers (2-4 years after medical school) and one registrar. The A and E EDs saw similar numbers of patients each year (47000 vs. 46000$)$. The types of illnesses of the study patients were similar at the two hospitals (Table 1). In both departments the Director/Consultant did not see patients during the study period.

The same investigator did all time measurements with data entered on written sheets. Time was measured to the nearest minute. Data was later entered on Quattro Pro computer spreadsheet for collation and calculations. Two tailed $t$-tests were carried out. Statistical significance was determined by confidence intervals of the means and their differences (Gardner \& Altman, 1989).

Table 1. Diagnoses of critical care patients

\begin{tabular}{lcc}
\hline & American & English \\
& $n$ & $n$ \\
\hline Chest Pain & 15 & 23 \\
Dyspnoea & 9 & 0 \\
(CHF, COPD, asthma) & & \\
Syncope (collapsed) & 1 & 6 \\
Trauma & 1 & 10 \\
Seizure & 1 & 0 \\
CVA & 4 & 1 \\
GI Bleed & 0 & 1 \\
Pneumothorax & 0 & 1 \\
Total & 31 & 42 \\
\hline
\end{tabular}




\section{RESULTS}

The length of time patients stayed in the ED differed significantly in E as compared with A (Fig. 1). In the E ED critical care patients spent only a short time (less thaf $30 \mathrm{~min}$ ) in the department; the decision about admission was prompt and made without extensive testing. In contrast, at the A ED critical care patients spent prolonged time $(3-4 \mathrm{~h})$ in the department.

The time spent by emergency physicians caring for critically ill patients wass significantly greater in the E compared with the A ED (Table 2). Emergency phys: icians at $\mathrm{A}$ spent less total time providing services and less time with the patient However, they spent more time on the phone and in patient care discussions orders. There was no significant difference in time spent charting. These resultis were the same when analysed by the subgroups of patients admitted to the wara or patients admitted to the critical care units.

Additional aspects of emergency physician services at the A ED were analysed (Table 3). There were time delays until the patient was seen by the emergencer

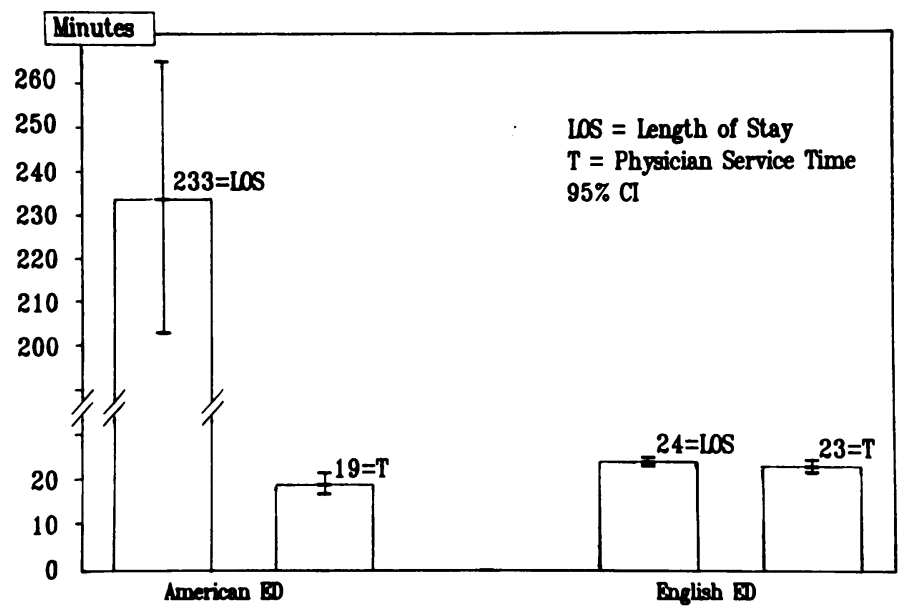

Fig. 1. Length of emergency physician critical care services in the emergency department.

Table 2. Emergency physician critical care (all patients)

\begin{tabular}{lccc}
\hline & $\begin{array}{c}\text { American } \\
\text { minutes }(95 \% \mathrm{CI})\end{array}$ & $\begin{array}{c}\text { English } \\
\text { minutes }(95 \% \mathrm{CI})\end{array}$ & $P$ \\
\hline Patient LOS* & $233(201,264)$ & $24(23,25)$ & $<0.01$ \\
Total EP Time & $19.2(16.8,21.6)$ & $23(21.6,24.4)$ & $<0.01$ \\
with patient & $12.4(10.3,14.5)$ & $17(15.8,18.2)$ & $<0.01$ \\
on phone & $1.8(1.4,2.2)$ & $1.2(1.1,1.3)$ & $<0.01$ \\
discuss/order & $1.8(1.4,2.2)$ & $1.1(0.8,1.4)$ & $<0.01$ \\
charting & $3.2(2.8,3.6)$ & $3.5(3.2,3.8)$ & n.s. \\
\hline
\end{tabular}

* Length of stay. 
Table 3. Breakdown of American emergency physician critical care services

\begin{tabular}{lcc}
\hline & Admit to CVU & Admit to ward \\
\hline Patient LOS* $^{*}$ & $197(102.5,291.5)$ & $262(190.4,333.6)$ \\
Delay til see EP & $4.9(2.5,7.3)$ & $9.2(4.6,13.8)$ \\
Total EP Service & $18.3(14.9,21.7)$ & $19.9(16.4,23.4)$ \\
$\quad$ with patient & $11.6(9.5,13.7)$ & $12.9(10.7,15.1)$ \\
$\quad$ 1st h & $9.5(6.9,12.1)$ & $10.8(8.1,13.5)$ \\
CVU MD time in $\mathrm{ED}^{\ddagger}$ & $12.1(8.8,15.9)$ & $6.7(5.5,7.9)$ \\
\hline
\end{tabular}

* Length of stay, ${ }^{+} 47 \%$ after patient admitted and waiting for bed, ${ }^{\ddagger}$ Time additional to EP services.

physician at $\mathrm{A}$ (there were no such delays at $\mathrm{E}$ ). The emergency physicians provided most bedside service in the first hour $(82 \%)$. One half of the patient's stay in the ED was after the patient had been admitted and was awaiting a bed. Additional physician service was provided in the A ED by critical care unit physicians.

\section{DISCUSSION}

Patients in E spent longer periods in the ED and with the emergency physician than patients in A.

The lengths of stay found in this study are consistent with those found in the literature. The emphasis in $\mathrm{E}$ is on prompt transfer of patients to the critical care unit. Gordon (personal communication) found short lengths of stay for critical care patients in the Edinburgh Royal Infirmary Emergency Department, Scotland, U. K. (mean $35 \mathrm{~min}$ in 1988 and mean $32 \mathrm{~min}$ in 1989). Emerson et al. (1988) also found short ED lengths of stay for chest pain patients admitted to the CCU at Westminster hospital in London, U. K. (mean $78 \mathrm{~min}$ ). He developed an advanced nurse triage system to lower those lengths of stay. American hospitals do not have the same promptness in the transfer of patients to the critical care unit. A national survey of American hospitals in 1988 found that one-fifth of hospitals had mean waits of $4 \mathrm{~h}$ or more for ICU beds to be available (Kellerman et al., 1990).

Lengths of stay of critical care patients in American EDs used to be brief. Pyo \& Watts (1970) found in Cleveland in that the lengths of stay in the ED were less than $1.5 \mathrm{~h}$ for chest pain patients. In the same year in Moss \& Goldstein (1970) found that $60 \%$ of myocardial infarction patients and $36 \%$ of non-myocardial infarction chest pain patients spent less than $15 \mathrm{~min}$ in the ED before transfer to the CCU. In 1972 Simon $e t$ al. found the mean length of stay for chest pain patients before transfer to the CCU was less than $60 \mathrm{~min}$. Tjoe \& Luria (1972) found a 90-min mean length of stay for critical care patients in the ED at St Luke's hospital in Cleveland. Schroeder et al. (1978) found an $89 \mathrm{~min}$ mean length of stay for chest pain patients in the ED at Stanford prior to transfer to the CCU.

Three factors were found in this study that prevented prompt admission of 
patients to the CCU (Fig. 2). The first delay was the 5 to 9-min wait until the emergency physician saw the patient. Saunders (1987) found similar waiting times for emergent patients to be seen by emergency physicians in his time study of Vanderbilt's ED. Such delays do not seem unreasonable since time is needed for $\stackrel{0}{\rightarrow}$ the patient's nurse to initiate the diagnostic work up that will take an average of $2 \mathrm{~h}$. The nurse will triage unstable patients directly to the physician (triage class crisis rather than emergent).

The second delay was the evaluation of the patient including a period of wait for test results. Saunders found lengths of stay were $400 \%$ greater for patients who had undergone laboratory tests compared with patients who did not undergo laboratory tests. This second delay could be decreased if the American emergency $\vec{\omega}$ physicians made clinical decisions on the need for hospitalization without labora- $\frac{\Phi}{\Phi}$ tory tests. Yet, this is not possible in the U.S.A. where uniformly there are $\stackrel{3}{.}$. utilization programs that seek to prevent hospitalization of patients who clearly do $\overrightarrow{0}$ not need such services. Thus third party payors mandate that physicians document the need for hospitalization by objective admission criteria, which for the most $f$ part are abnormal laboratory test results.

The third delay was the wait for the hospital bed to be open. The delay found $\vec{D}$ in this study $(2 \mathrm{~h})$ is representative of the norm. A 1988 national survey showed $\frac{\pi}{0}$ one-fifth of American EDs have mean waits greater than $4 \mathrm{~h}$ for ICU beds to be $\stackrel{\mathbb{D}}{\mathbb{D}}$ available (Kellerman et al., 1990). There is a scarcity of critical care beds at Americap hospitals (Singer et al., 1983; Strauss et al., 1986; Teres \& Steingrub, 1987). Patients wait in the ED until they are stabilized enough for a bed in a non-critical care area or until other patients can be moved out of the critical care unit to free a bef The American College of Emergency Physicians' task force on overcrowding has not found any simple answers to this problem (ACEP, 1990). Unfortunately the extent to which these delays affect patient care adversely have not been documented.

Despite the difference of $3.5 \mathrm{~h}$ between the two hospitals in length of stay, the $\stackrel{2}{\overrightarrow{0}}$ total length of physician services differed by only $4 \mathrm{~min}$. There was not a direct 3 relationship between length of stay and the length of physician services. Most of the physician services were provided at A during the first hour. This supports

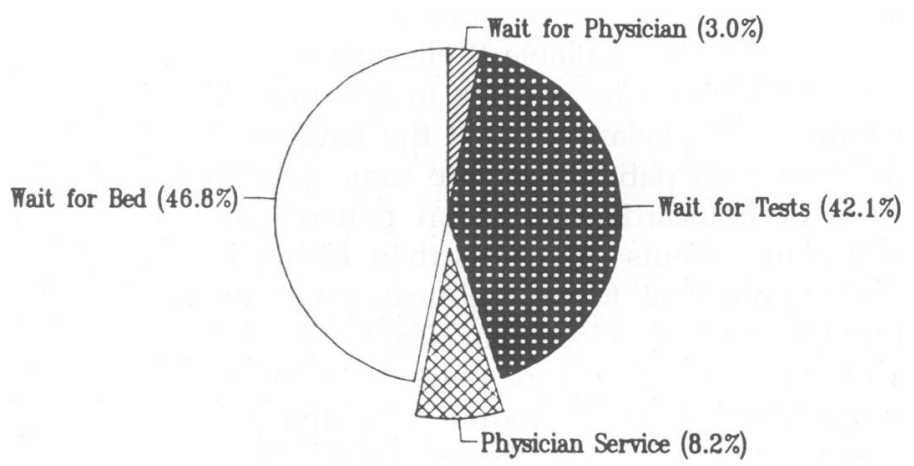

Fig. 2. Delays in admission of critical care patients. 
the concept of an initial relatively intense physician evaluation followed by a second phase of continuing care/observation of lower intensity of service (Graff \& Radford, 1990a, b).

Two factors may explain the larger amount of emergency physician services at $\mathrm{E}$ compared with A (Table 2). First is the difference between American and English physicians in the use of diagnostic tests. American physicians will not usually make the final decision on hospital admission until all the test results are back and only a short time is spent on the history and physical exam in action. The physician's initial evaluation focuses on determining which tests to order. For social or medicolegal reasons the physician needs the test results to document illness or confirm the physician's diagnostic impression of the cause of the patient's illness. This contrasts to English physicians who rely heavily on the patient's history and physical examination. Much fewer tests are ordered. For example, at A disposal of the chest pain patient with possible myocardial infarction and nondiagnostic EKG was determined by the patient's cardiac enzyme results. The patient with positive enzymes was admitted to the CCU while the patient with negative enzymes was admitted to an intermediate monitored bed unit. This contrasts with $\mathrm{E}$ where patients with possible myocardial infarction were admitted to the critical care unit after the initial evaluation without waiting or considering the results of cardiac enzymes. The second factor explaining the longer time spent with patients by English compared with American emergency physicians is the type of physician staffing. E used relatively inexperienced physicians (house officers with 2-4 years post-medical school) while A used full time emergency physician faculty (mean 12 years post-medical school). Physicians in training are not as efficient as experienced physicians. Mosdossy \& Granfield (1990) found house staff could see 1.25 patients per hour. This is less than the standard for experienced emergency physicians which ranges from 2.5 to 3 patients per hour, (Hannas, 1973; Cue \& Inglis, 1978; Van de Leuv, 1978, Mills, 1986; Van de Leuv, 1987; Franaszek, 1988).

Provision of critical care services in the ED for extended periods of time has implications for the staffing and equipping of EDs. More experienced physicians are needed in EDs such as A.

Critically ill patients are in the department for a prolonged time period and potentially dangerous therapy such as thrombolysis may be started in the department. Nurses with more advanced skills similarly are needed in EDs where patients cannot be transferred to the CCU promptly. Use of inexperienced physicians without direct supervision may be adequate in EDs where the patients spend only a brief time before transfer (e.g., as in E), although research into emergency medicine malpractice has shown that inexperienced, unsupervised physicians are at a greater risk of errors (Trautlein et al., 1984; Rusnak et al., 1989). Advance monitoring systems are needed in EDs providing critical care services for prolonged periods: continuous vital signs monitoring (blood pressure, pulse, oximetry), and/or ECG monitors with arrhythmia recognition, memory, and alarms. Neither the physician nor the nurse is in constant attendance of patients who are in the ED for prolonged periods. CCUs have one to one or one to two nurse to patient ratios (SCCM, 1988) but EDs do not staff at this level; only during brief time periods, e.g. in a crisis situation such as cardiopulmonary arrest or shock 
does a high nurse to patient ratio pertain. Most physician critical care services were provided during an initial period of stabilization of the patients, although physician services were also administered later on in the patients' stay. EDs providing extended critical care services need procedures and staffing to provide these services.

Physician service times for even similar tasks vary widely for different specialties (Hsiao et al., 1988; Braun et al., 1990). This study showed very different staffing patterns for two EDs providing critical care services. The proper amount of emergency physician service time remains to be determined for critical care patients kept in EDs on an extended basis. This needs to be calculated irrespective of whether this occurs for diagnostic evaluation or for waiting for the opening of hospital beds.

\section{CONCLUSIONS}

Emergency physicians at $\mathrm{E}$ provided critical care services almost continuously during a short stay in the ED. Emergency physicians at A provided services intermittently with most services during an initial period of stabilization. Further study is necessary to identify what factors contribute to these different approaches to critical care.

\section{REFERENCES}

ACEP Overcrowding Task Force on Overcrowding (1990) Measures to deal with Emergency Department Overcrowding. Annals of Entergency Medicine 19, 944-945.

Baldrige P. (1966) The nurse in triage. Nursing Outlook 14, 46-48.

Braun P., Hsiao W. C., Becker E. R. \& DeNicola M. (1990) Evaluate and management services in a resources-based relative value scale. Journal of the Anterican Medical Association 260, 2404-2417.

Cue F. \& Inglis R. (1978) Improving the operations of the emergency department. Journal of the American Hospital Association 52, 110-119.

Emerson P. A., Wyatt J., Dillistone L., Crichton N. \& Russell N. J. (1988) ACORN, an expert system for nurses to make admission decisions on chest pain patients presenting to an accident and emergency department. Medical Decision Making 8, 334.

Engstrom T. (1977) Emergency department encounter data, 1975-1976, Wisconsin. Department of Health Services, December.

Franaszek J. B. (1988) College testifies before the Council on Graduate Medical Education (COGME) on the current shortage in emergency physicians. Testimony November 20, 1987 at hearing of the COGME. American College of Emergency Physicians Nerus 7, 1, 20.

Gardner M. J. \& Altman D. G. (1989) Statistics with confidence - confidence intervals and statistical

guidelines, pp. 6-27, 112-113. British Medical Journal, London.
Gibson G. (1970) Entergency medical services in the Chicago area. Center for Health Administration of

Studies, The University of Chicago, 1970.
Gifford M. J., Franaszek J. B. \& Gibson G. (1980) Emergency physician's and patients' assessments: No

urgency of need for medical care. Annals of Emergency Medicine 9, 502-507.
Graff L. G., Mucci D. \& Radford M. J. (1988) Decision to hospitalize: objective diagnosis-related group ${ }^{0}$ criteria versus clinical judgment. Annals of Energency Medicine 17, 943-952.

Graff L. G. \& Radford M. J. (1990a) Decision to hospitalize patients with suspected appendicitis: $\stackrel{\mathbb{D}}{\mathscr{D}}$ 
physicians' clinical judgment versus objective diagnosis-related group criteria. Annals of Emergency Medicine 19, 607.

Graff L. G. \& Radford M. J. (1990b) Formula for emergency physician staffing. American Journal of Emergency Physicians 8, 194-199.

Graves H. B. (1972) ACEP surveys hospital triage systems. Journal of the American College of Emergency Physicians 1(6), 31-33.

Hannas R. R. (1973) Staffing the emergency department. Hospitals 47, 83-86.

Hsiao W. C., Yntema D. B. \& Braun P. Measurement and analysis of intraservice work. Journal of the American Medical Association 260, 2361-2370.

Jacobs A. R., Gavett J. W. \& Wersinger R. (1971) Emergency department utilization in the urban community: implications for community ambulatory care. Journal of the American Medical Association 206, 307-312.

Kellermann A., Andrulis D. \& Hackman B. Hospital and emergency department overcrowding: results of a national survey. Annals of Emergency Medicine 19, 1217-1218.

Kluge D. N., Wegryn R. L. \& Lemleyu B. R. (1965) The expanding emergency department. Journal of the American Medical Association 191, 801-805.

LeTourneau B., Blegen C. N., Clinton J. E. \& Ruiz E. (1980) Critical care in an emergency department. Annals of Energency Medicine 9, 126-130.

Lister J. (1986) Shattuck Lecture - The politics of medicine in Britain and the United States. New England Journal of Medicine 315, 168-174.

Mendenhall R. C. (1979) Emergency Physicians Practice Study Report. University of Southern California School of Medicine, September 14.

Mills J. P. (1986) The emergency department: organization and staffing. In: Principles and Practice of Emergency Medicine, 2nd Ed. (ed. Schwartz, G. R.), pp. 623. Saunders Philadelphia.

Mosdossy G. J. \& Granfeld A. (1990) The emergency department as a clinical teaching unit: a time flow study of emergency medicine residents. Journal of Emergency Medicine 8, 367.

Moss A. J. \& Goldstein S. (1970) The prehospital phase of acute myocardial infarction. Circulation 43, 737-742.

Navarro V. (1985) The public/private mix in the funding and delivery of health services: an international survey. American Journal of Public Health 75(11), 1318-1320.

Parker S. (1978) Emergency room utilization at Hermann Hospital. Texas Medicine 74, 1-7.

Pyo Y. H. \& Watts R. W. (1970) A mobile coronary care unit: an evaluation for its need. Annals of Internal Medicine 73, 61-66.

Reinhardt U. E. (1985) The compensation of physicians: approaches used in foreign countries. Quarterly Revievo Bulletin 366-377.

Rosen P. et al. (1974) A method of triage within an emergency department. Journal of the Anterican College of Energency Physicians 3(2), 85-86.

Rusnak R. A., Stair T. O., Hansen K. \& Fastow J. S. (1989) Litigation against the emergency physician: common features in cases of missed myocardial infarction. Annals of Emergency Medicine 18, 1029-1034.

Rutherford W. H. (1983) Accident and emergency medicine in the United Kingdom. American Journal of Emergency Medicine 1, 107-109.

Saunders C. E. (1987) Time study of patient movement through the emergency department: sources of delay in relation to patient acuity. Annals of Energency Medicine 16, 1244-1248.

Schroeder J. S., Lanb I. H. \& Hu M. (1978) The prehospital course of patients with chest pain: analysis of the prodromal, symptomatic, decision-making, transportation, and emergency room periods. American Journal of Medicine 64, 742-748.

Simon A. B., Feinleib M. \& Thompson H. K. (1972) Components of delay in the prehospital phase of acute myocardial infarction. American Cardiology 30, 476-481.

Singer D. E., Carr P. L., Mullery A. G. \& Thibault G. E. (1983) Rationing intensive care - physician responses to a resource shortage. New England Journal of Medicine 309, 1155-1160.

Strauss M. J., LoGerfo J. P., Yeltatzie J. A., Temkin N. \& Hudson L. D. (1986) Rationing of intensive care unit services: an everyday occurrence. Journal of the American Medical Association 255, 1143-1146.

Task Force on Guidelines Society of Critical Care Medicine (1988) Recommendations for services and personnel for delivery of care in a critical care setting. Critical Care Medicine 16, 809-811. 
Teres D. \& Steingrub J. (1987) Can intermediate care substitute for intensive care? Critical Care Medicing $15,280$.

Tjoe S. \& Luria M. H. (1972) Delays in reaching the cardiac care unit: an analysis. Chest 61, 617-621 Trautlein J. J., Lambert R. L. \& Miller J. (1984) Malpractice in the emergency department - review of 200 cases. Annals of Emergency Medicine 13, 709-711.

van de Leuv J. H. (1978) Staffing the emergency department. In Emergency Department Organization and Management 2nd Ed (eds Jinkins A. L. \& van de Leuv J. H.), pp. 35. Mosby, St Louis.

van de Leuv J. H. (1987) Physician staffing. In Management of Emergency Services (ed. van de Leuv J. H.) pp. 16-28. Aspen Publications, Aspen.

Vickery D. M. (1975) Triage. Robert J Brady, Co., Bowie.

Walker L. L. (1975) The emergency department - entry point into the health care system. Journal of the American College of Emergency Physicians 4, 129-132.

Weinerman E. R. et al. (1966) Yale studies in ambulatory medical care: use of hospital emergency services. American Journal of Public Health 56, 1037-1056.

Yealy D. M., DeHart D. A., Ellis G. et al. (1989) A survey of observation units in the United States $\stackrel{\mathbb{D}}{\Omega}$ American Journal of Emergency Medicine 7, 576-580. 